\title{
Crustal structure beneath Liaoning province and the Bohai Sea and its adjacent region in China based on ambient noise tomography
}

\author{
Guang-hua Pang $\cdot$ Ji-Kun Feng $\cdot$ Jun Lin
}

Received: 30 October 2016/Accepted: 7 February 2017/Published online: 8 March 2017

(C) The Author(s) 2017. This article is published with open access at Springerlink.com

\begin{abstract}
The velocity structure of the crust beneath Liaoning province and the Bohai sea in China was imaged using ambient seismic noise recorded by 73 regional broadband stations. All available three-component time series from the 12-month span between January and December 2013 were cross-correlated to yield empirical Green's functions for Rayleigh and Love waves. Phasevelocity dispersion curves for the Rayleigh waves and the Love waves were measured by applying the frequencytime analysis method. Dispersion measurements of the Rayleigh wave and the Love wave were then utilized to construct 2D phase-velocity maps for the Rayleigh wave at 8-35 s periods and the Love wave at 9-32 s periods, respectively. Both Rayleigh and Love phase-velocity maps show significant lateral variations that are correlated well with known geological features and tectonics units in the study region. Next, phase dispersion curves of the Rayleigh wave and the Love wave extracted from each cell of the 2D Rayleigh wave and Love wave phase-velocity maps, respectively, were inverted simultaneously to determine the 3D shear wave velocity structures. The horizontal shear wave velocity images clearly and intuitively exhibit that the earthquake swarms in the Haicheng region and the
\end{abstract}

G. Pang $\cdot$ J. Lin $(\bowtie)$

College of Instrumentation and Electrical Engineering, Jilin University, Changchun 130061, China

e-mail: pghua7@163.com

J.-K. Feng

School of Earth and Space Sciences, University of Science and Technology of China, Hefei 230026, China

J. Lin

Key Laboratory of Geo-Exploration and Instrumentation of Education Ministry, Jilin University, Changchun 130061, China
Tangshan region are mainly clustered in the transition zone between the low- and high-velocity zones in the upper crust, coinciding with fault zones, and their distribution is very closely associated with these faults. The vertical shear wave velocity image reveals that the lower crust downward to the uppermost mantle is featured by distinctly high velocities, with even a high-velocity thinner layer existing at the bottom of the lower crust near Moho in central and northern the Bohai sea along the Tanlu fault, and these phenomena could be caused by the intrusion of mantle material, indicating the Tanlu fault could be just as the uprising channel of deep materials.

Keywords Crustal structure - Ambient noise tomography · Earthquake swarm $\cdot$ Liaoning Province $\cdot$ Bohai Sea

\section{Introduction}

The Tancheng-Lujing (Tanlu: illustrated in Fig. 1b) fault zone is considered as the deep faults that penetrate the Earth's crust into the upper mantle (Wang et al. 2000), and go straight through the Bohai sea into Liaoning Province along the NNE direction from the south to the north. The Bohai sea, locates in the eastern part of the North China Craton (NCC), is an important window for understanding the destruction process of the NCC ( $\mathrm{Li}$ et al. 2010b; Zhu et al. 2011). The southern Bohai sea hosts a complex tectonic system where the Tanlu fault belt and the NWstriking fault of the Zhangjiakou-Penglai seismic zone intersect with the fault branches in different directions (Qi et al. 2008; Qi and Yang 2010), as shown in Fig. 1b, and is characterized by extremely dense small earthquake activity. The areas near the Tangshan in Hebei province and the 
Haicheng in Liaoning province are also characterized by high-frequency and high-strength seismic activities (Zhu $1980)$ as wells as moderate and small earthquakes. Prior studies have shown that the occurrence of earthquakes is closely associated with the structure and properties of the regional crust and upper mantle. (e.g. Obermann et al. 2014; Jiang et al. 2014; Wang et al. 2013; Xu et al. 2014; Yu et al. 2010, 2014; Zhang et al. 2014). Therefore, the study on velocity structure in active seismic tectonic belts is important for finding regularity of earthquake activity.

The study area (especially the Bohai sea) (Fig. 1), including Liaoning province, the Bohai sea and its adjacent region, has been studied by earthquake-based body-wave and surface-wave tomography at different scales (e.g. Li et al. 2006; 2011; Huang et al. 2009; Zhang et al. 2007; Lü et al. 2016; Tian et al. 2009) and joint land-sea seismic surveys (e.g. Hao et al. 2013; Liu et al. 2015). The abovementioned studies have provided good understandings for the deep structure of the study area. However, the traditional seismic waveform analysis methods have several disadvantages, including a few restrictions on sparse and uneven distributions of earthquake sources, and uncertainties of earthquake locations and study regions. In addition, the earthquake-based surface-wave tomography has a poor ability to obtain reliable constraints on crustal structure at shallow depths; the joint land-sea seismic survey is also restricted by the locations of the profiles and fails to reflect the overall change of the Bohai sea's deep structure. In contrast, ambient noise tomography (ANT), as a powerful new tool in seismology, could avoid abovedescribed shortcomings to illuminate the velocity structure of the Earth, and it has been widely applied in many Chinese regions (e.g. Li et al. 2009, 2010a; Yao et al. 2008; Zheng et al. 2008). The theoretical work and applications of ANT have been published by Campillo and Paul (2003), Weaver and Lobkis (2004), Weaver (2005), Shapiro and Campillo (2004), Shapiro et al. (2005), Roux et al. (2005) and Sabra et al. (2005). Although this method has been applied in the areas involved in our study area, the results only obtain local linear crustal velocity structures (Cheng et al. 2011) or reflect major overall structures (e.g. Sun et al. 2010; Zheng et al. 2011). Small-scale imaging in our study would aid efforts to identify the local velocity change in smaller geological units.

In this paper, we collected three-component seismograms from broadband stations to retrieve both the Rayleigh wave and the Love wave phase-velocity tomography through ambient noise cross-correlation. The resulting Rayleigh wave and Love wave phase-velocity maps generally show good correlations with major geological and tectonic units in the study region. Then, we inverted threedimensional (3-D) shear wave velocity structures from the surface down to $46 \mathrm{~km}$ based on the Rayleigh and Love wave velocities simultaneously and discuss their geological implications and relationship to the time-space distribution of earthquake swarms.

\section{Data preprocessing and time-domain analysis}

Continuous data (Zheng et al. 2009) from all three components (east- $\mathrm{E}$, north $-\mathrm{N}$, vertical-Z) were collected from 71 broadband stations and recorded from January 2013 to December 2013. A catalogue of earthquakes recorded from January 2010 to February 2015 was used in this study and was obtained from the "China Earthquake Data Center" (the earthquakes whose magnitudes less than 4.5 and greater than 1.0 are defined as small earthquakes in this paper). The station locations range from $117^{\circ} \mathrm{E}$ to $127^{\circ} \mathrm{E}$ longitude and $37^{\circ} \mathrm{N}$ to $43.5^{\circ} \mathrm{N}$ latitude, covering Liaoning province, most of the Bohai sea and its surroundings in China. The distribution of the seismic stations and the epicentral distribution of the small earthquakes are illustrated in Fig. 1a and b, respectively.

Our preprocessing scheme was similar to that described in Bensen et al. (2007), consisting of three-component preprocessing (LHE-E, LHN-N and LHZ-Z) of the daily noise records before cross-correlation. First, all component seismograms (E, N, Z) were separated into 2-hr segments and resampled to $1 \mathrm{~Hz}$, followed by removal of the mean, trend, and instrument response from the daily noise time series. Next, seismic data were band-pass-filtered between 2.25 and $60 \mathrm{~s}$. Subsequently, time-domain normalization was applied to remove the effects of earthquakes and other irregularities using a weighted running average method. Finally, spectral whitening was used to avoid significant spectral imbalance and to broaden the bandwidth of the ambient noise.

After all these preprocessing steps were performed, component cross-correlations of the daily records (E-E, E$\mathrm{N}, \mathrm{N}-\mathrm{E}, \mathrm{N}-\mathrm{N}, \mathrm{Z}-\mathrm{Z}$ ) between each station pair were carried out and one year of daily cross-correlations were stacked to obtain the final cross-correlations. The cross-correlations for the N-N, N-E, E-N, and E-E components were then rotated into the radial $(\mathrm{R}-\mathrm{R})$ and the transverse $(\mathrm{T}-\mathrm{T})$ components using a rotation matrix (e.g. Lin et al. 2007). Figure 2 presents an example of two cross-correlation record sections between LZH and other stations for the Z$\mathrm{Z}$ component and the $\mathrm{T}-\mathrm{T}$ component. Subsequently, the positive and negative components of the cross-correlations were stacked to determine the so-called symmetric components and enhance the signal-to-noise ratio (SNR). Finally, a negative time derivative was adopted to obtain the empirical Green's function (EGF) of the Rayleigh wave from cross-correlations of the $\mathrm{Z}-\mathrm{Z}$ component and the EGF 

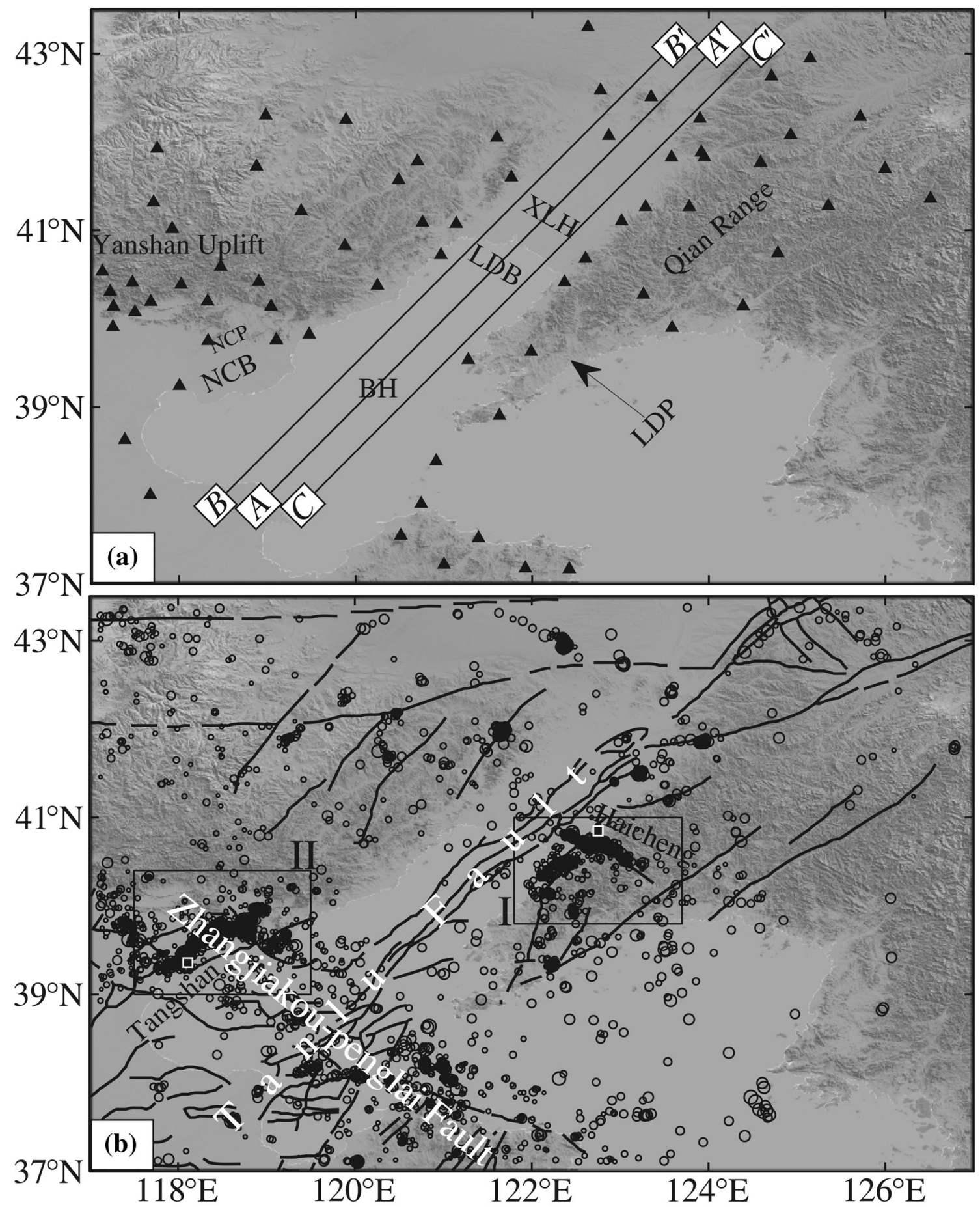

Fig. 1 a The distribution of seismic stations used in this study and the background tectonic map of the study area: the triangles represent broadband stations; $X L H$ Xialiaohe basin, $B H$ Bohai sea (Bohai bay basin), $N C B$ North China basin, $N C P$ North China plain, $L D B$ Liaodong bay, $L D P$ Liaodong peninsula; the black lines are the section lines of the vertical profiles $\left(A-A^{\prime}, B-B^{\prime}\right.$ and $\left.C-C^{\prime}\right)$ shown in Fig. 10 ; $\mathbf{b}$ The epicentral distribution of earthquakes and fault systems in the study area: the black lines represent the faults; the open circles denote the earthquakes that occurred in 2010-2015, of which the focal depths are less than $46 \mathrm{~km}$ and the $M_{\mathrm{L}}$ magnitudes are less than 4.5 and greater than 1.0; the circle sizes are proportional to the earthquake magnitudes. Black rectangular frames I and II are the scopes of the horizontal profiles in Haicheng region and Tangshan region, respectively; black rectangular frames I and II are the scopes of the horizontal profiles in Haicheng region and Tangshan region shown in Figs. 8 and 9, respectively 

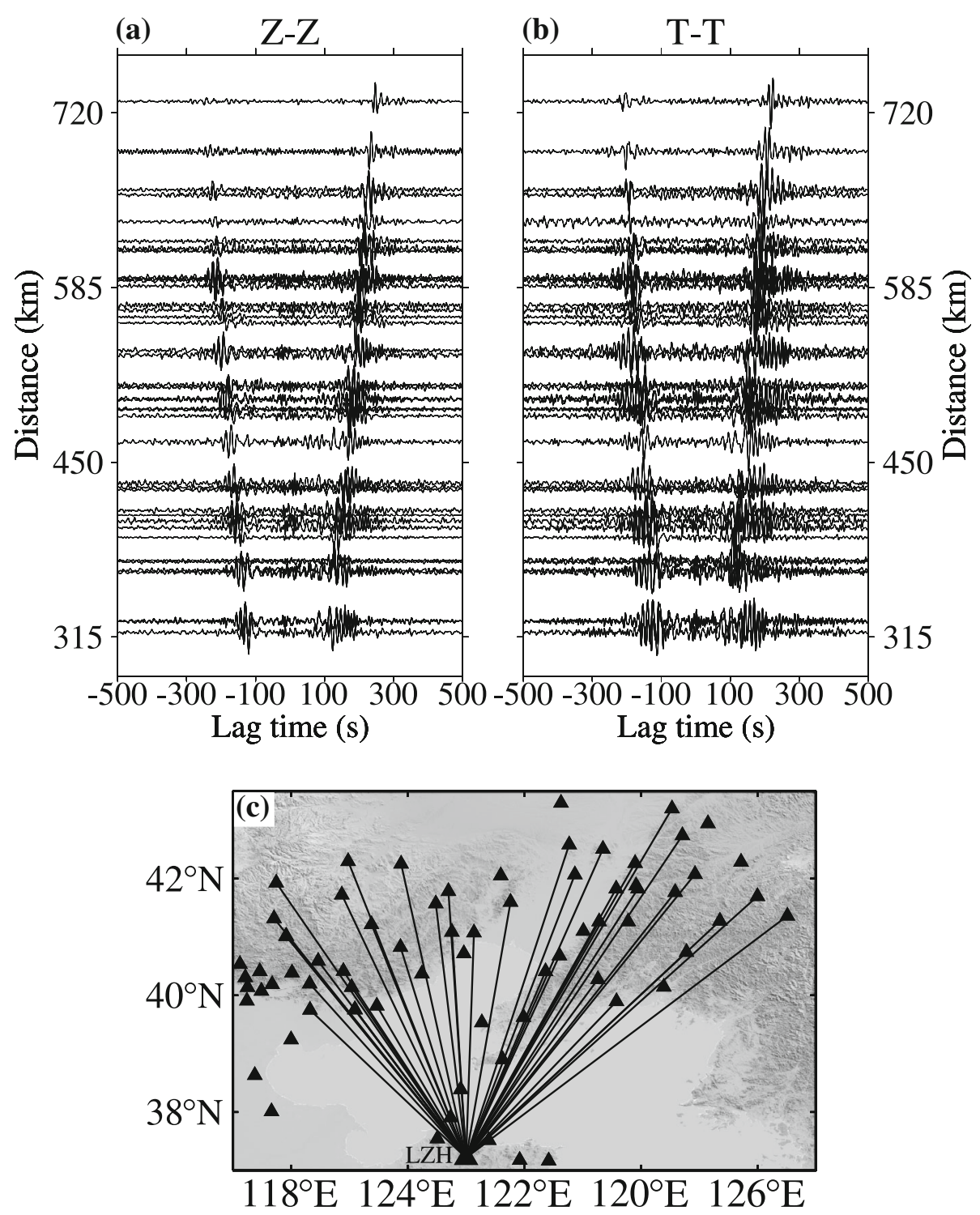

Fig. 2 a 3-40 s band-pass-filtered record between station LZH and other stations with vertical-vertical cross-correlations. b Same as Fig. 2a but for transverse-transverse cross-correlations. c The ray path distribution

of the Love wave from cross-correlations of the $\mathrm{T}-\mathrm{T}$ component.

Because the Rayleigh and Love wave Green's functions have the same form, the same phase-velocity analysis can be applied to both Rayleigh and Love waves (Lin et al. 2007). We estimated the Rayleigh wave and Love wave phase-velocity dispersion curves using a modified far-field approximation of the image transformation analysis technique developed by Yao et al. (2006) that can rapidly track the entire dispersion curve. Figure 3 are examples of the phase-velocity dispersion curves. It shows that signal arrival times on the $\mathrm{Z}-\mathrm{Z}$ cross-correlation and the $\mathrm{R}-\mathrm{R}$ cross-correlation are quite similar, as both of them contain the Rayleigh wave signal. T-T cross-correlations in Fig. 3a and their corresponding dispersions in Fig. 3b exhibit the expected earlier Love wave arrival.

To assess the reliability of the dispersion measurements for tomography, three criteria were imposed. First, the crosscorrelation measurements with a signal-to-noise ratio below 5 were removed. Second, all dispersion measurements with $\Delta<2 V_{\max } T_{\max }$ were discarded [where $\Delta$ is the epicentral distance (in $\mathrm{km}$ ) and $V_{\max }$ is the assumed maximum surfacewave velocity (in $\mathrm{km} / \mathrm{s}$ )] to avoid spurious signals from interference between the causal and anticausal parts (Shapiro et al. 2005; Lin et al. 2007). Third, considering the reasonable shape of the dispersion curves based on the cluster analysis (e.g. Ritzwoller and Levshin 1998) and the morphological analysis, notable abnormal measurements were excluded. 


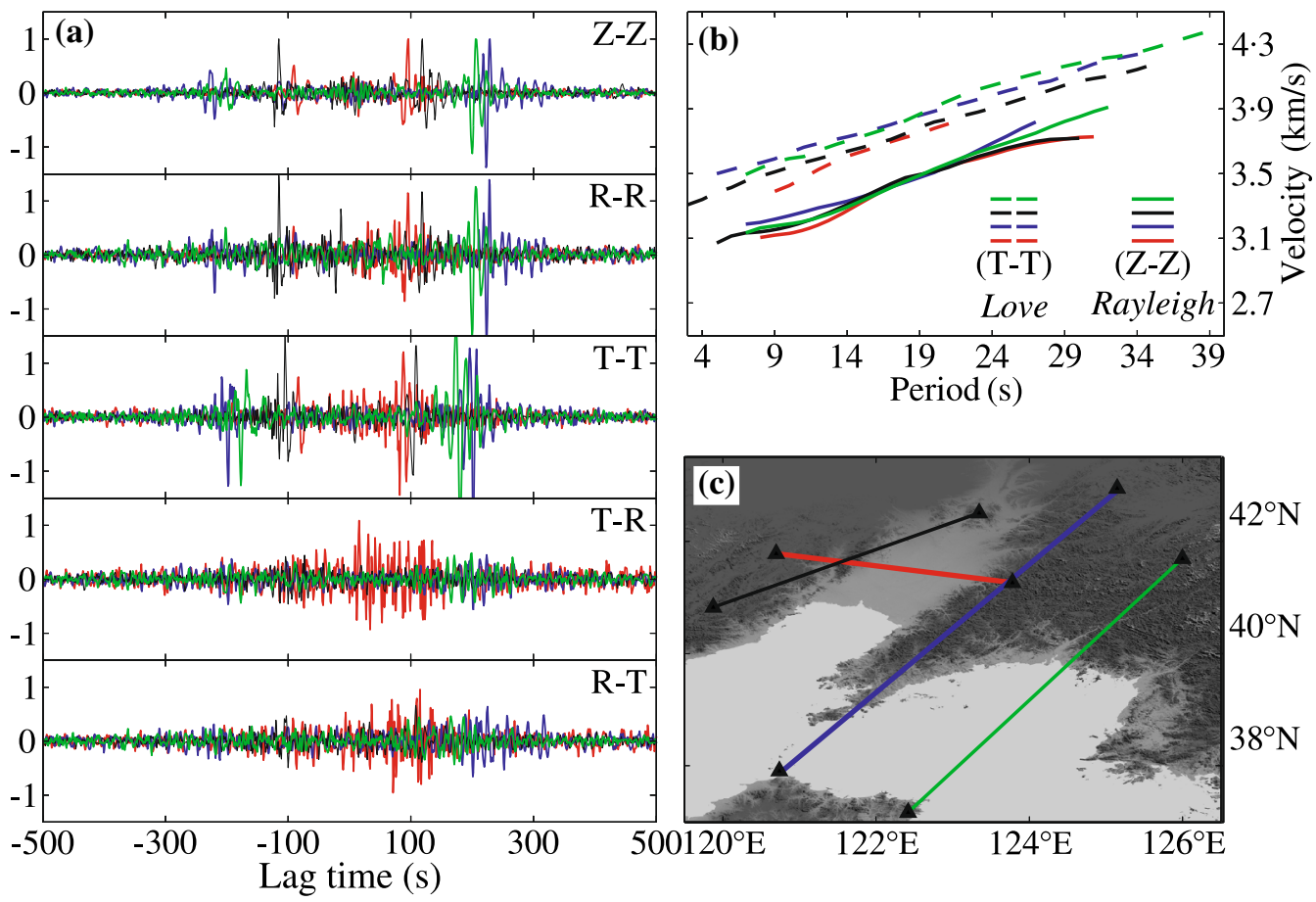

Fig. 3 Examples of the phase-velocity dispersion curves. a The 2.25-60 s band-pass-filtered cross-correlations for Z-Z, R-R, T-T, T-R and RT. Z, R and T denote vertical, radial and transverse sections, respectively. b Phase-velocity dispersion curves; the solid lines and dashed lines denote phase-velocity dispersion curves of the Rayleigh waves and the Love waves, respectively; $\mathbf{c}$ the interstation paths for the phase-velocity measurements. The coloured waveforms in (a), the coloured curves in (b) and the rays in (c) correspond to each other

\section{Phase-velocity tomography}

Figure 4 shows the path coverage at periods 9,15 , and $20 \mathrm{~s}$ for the Rayleigh wave and the Love wave corresponding to the reliable dispersion measurements. The path distribution is uniform and dense in most of the study area except for the edge of the study area. Before inverting Rayleigh wave and Love wave phase velocities, the checkerboard tests were conducted to investigate the reliability of the tomography results. Figure $5 \mathrm{~g}$ shows a theoretical velocity model with the grid of $1.5^{\circ} \times 1.5^{\circ}$ as the real model. The size of the alternating high-velocity and low-velocity cells is $1.5^{\circ}$. Positive or negative velocity perturbations of $5 \%$ are assigned to each cell with an average velocity of $4 \mathrm{~km} / \mathrm{s}$ at different periods. Finally, the synthetic data of the phase velocities were calculated according to actual paths at each period. The checkerboard tests using the path coverage at periods between 3 and $40 \mathrm{~s}$ are conducted. The checkerboard tests for the Rayleigh wave at periods between 8 and $35 \mathrm{~s}$ and for the Love wave at periods between 9 and $32 \mathrm{~s}$ suggest that the input model could be satisfactorily recovered in most parts of the study area including Bohai sea. We show that the test results for the Rayleigh wave and the Love wave at 9, 15 and $20 \mathrm{~s}$ periods in Fig. 5, which corresponds to the path coverages in Fig. 4 and the phase velocity maps in Fig. 6 .
We inverted the Rayleigh wave and Love wave phasevelocity dispersion measurements at the 8-35 s and 9-32 s periods, respectively, and obtained the Rayleigh wave and Love wave phase-velocity maps at different periods using the technique of Tarantola and Nercessian (1984) and Yao et al. (2006, 2010). Both the Rayleigh wave and Love wave phase velocity maps at 9, 14 and $20 \mathrm{~s}$ are shown in Fig. 6 . At the short period of $9 \mathrm{~s}$, the Rayleigh wave maps (Fig. 6a) and Love wave maps (Fig. 6b) exhibit broadly similar features, which can confirm each other and validate the reliability of the results simultaneously. The very low velocities are clearly observed beneath the Xialiaohe basin, Bohai bay basin and North China basin and are well associated with thick sediments, as shown by comparing Fig. $6 \mathrm{a}$ and $\mathrm{b}$ with the sediment thicknesses based on the Crust1.0 (Laske et al. 2015; Fig. 6g), while the Yanshan uplift and Qian range show higher velocities than the basins at this period. This contrast is to be expected as a result of the large differences in the elastic properties of sediments and crystalline bedrock (Lin et al. 2012). Figure $6 \mathrm{c}$ and $\mathrm{d}$ show that the velocity distribution patterns are slightly different between the Rayleigh and Love wave maps at $15 \mathrm{~s}$. The low-velocity anomaly beneath the Bohai bay basin is still notable in both maps, but becomes less prominent. The general pattern of $15 \mathrm{~s}$ Love wave velocity distribution (Fig. 6c) is more affected by the sediments 

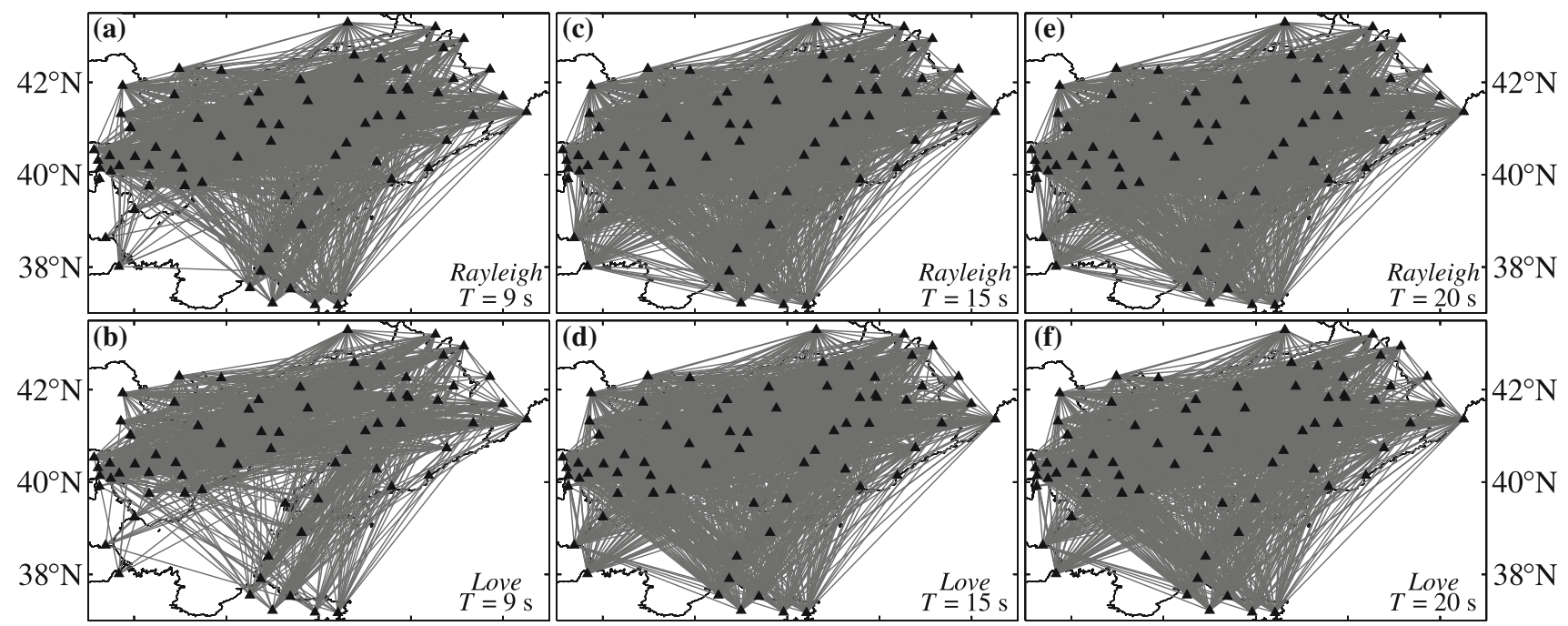

$118^{\circ} \mathrm{E} 120^{\circ} \mathrm{E} 122^{\circ} \mathrm{E} 124^{\circ} \mathrm{E} 126^{\circ} \mathrm{E} 118^{\circ} \mathrm{E} 120^{\circ} \mathrm{E} 122^{\circ} \mathrm{E} 124^{\circ} \mathrm{E} 126^{\circ} \mathrm{E} 118^{\circ} \mathrm{E} 120^{\circ} \mathrm{E} 122^{\circ} \mathrm{E} 124^{\circ} \mathrm{E} 126^{\circ} \mathrm{E}$

Fig. 4 The path coverage at different periods for Rayleigh wave and Love wave. a Path coverage for the Rayleigh wave at period 9 s; $\mathbf{c}$ same as Fig. 4a but for $T=15 \mathrm{~s}$; d same as Fig. 4a but for $T=20 \mathrm{~s} ; \mathbf{b}, \mathbf{d}$ and $\mathbf{f}$ same as a and $\mathbf{c}$ and e, respectively, but for Love wave

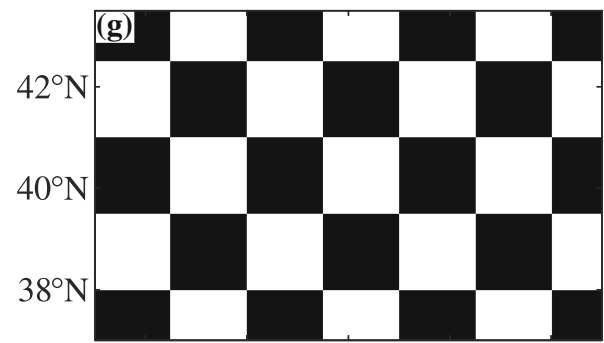

$-5 \quad 0 \quad 5$
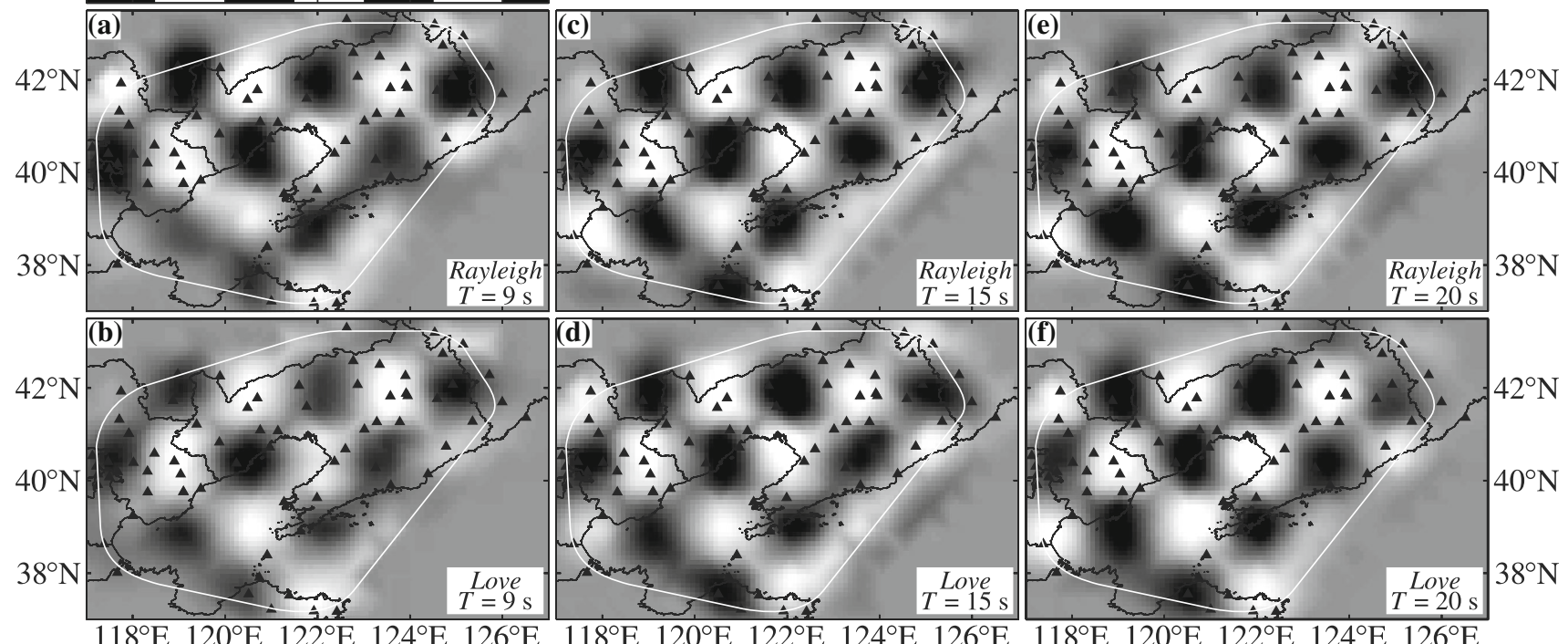

$118^{\circ} \mathrm{E} 120^{\circ} \mathrm{E} 122^{\circ} \mathrm{E} 124^{\circ} \mathrm{E} 126^{\circ} \mathrm{E}$

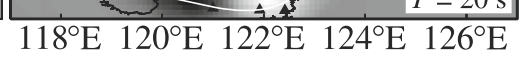

Fig. 5 The theoretical model and the results of the checkerboard test. a The inversion result of the Rayleigh wave for $T=9 \mathrm{~s}$ path coverage; c same as Fig. 5a but for $T=16 \mathrm{~s}$; e same as Fig. 5a but for $T=20 \mathrm{~s} ; \mathbf{b}, \mathbf{d}$ and $\mathbf{f}$ same as a and $\mathbf{c}$ and e, respectively, but for Love wave; g Theoretical model with the grid of $1.5^{\circ}$. The white closed lines represent the study area. The bar represents the velocity anomaly in percentage compared to the reference velocity

compared to the $15 \mathrm{~s}$ Rayleigh wave map (Fig. 6d); this difference certainly contributes to the higher sensitivity to shallow depths of the Love wave compared to that of the Rayleigh wave at the same period. At $20 \mathrm{~s}$ period, the lateral inhomogeneity of both the Rayleigh wave and the Love wave phase velocity distribution diminishes, and the imprint of the sedimentary layers disappears completely. In addition, high-velocity anomalies in the southern the 

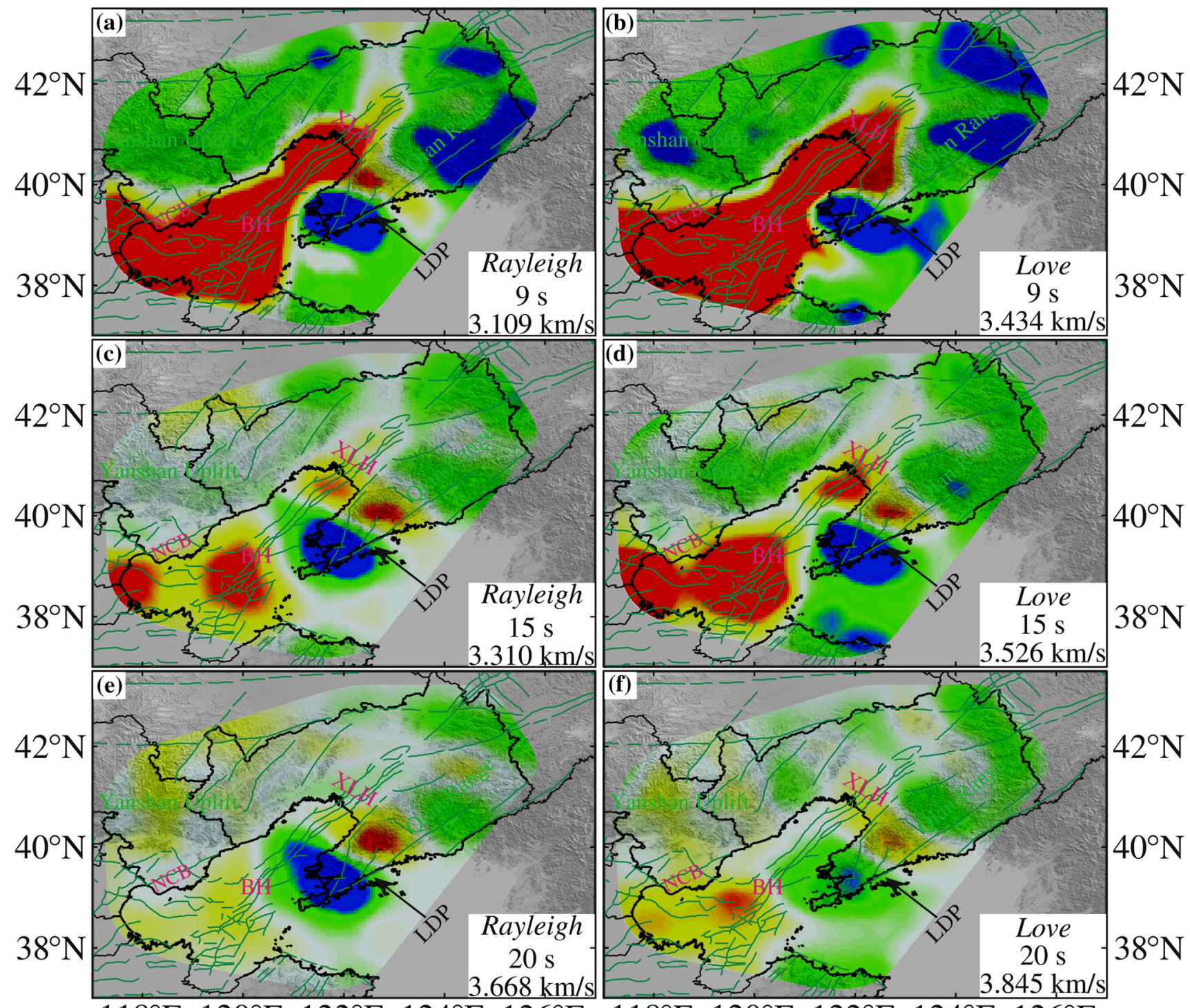

$118^{\circ} \mathrm{E} 120^{\circ} \mathrm{E} 122^{\circ} \mathrm{E} 124^{\circ} \mathrm{E} 126^{\circ} \mathrm{E} \quad 118^{\circ} \mathrm{E} 120^{\circ} \mathrm{E} 122^{\circ} \mathrm{E} 124^{\circ} \mathrm{E} 126^{\circ} \mathrm{E}$
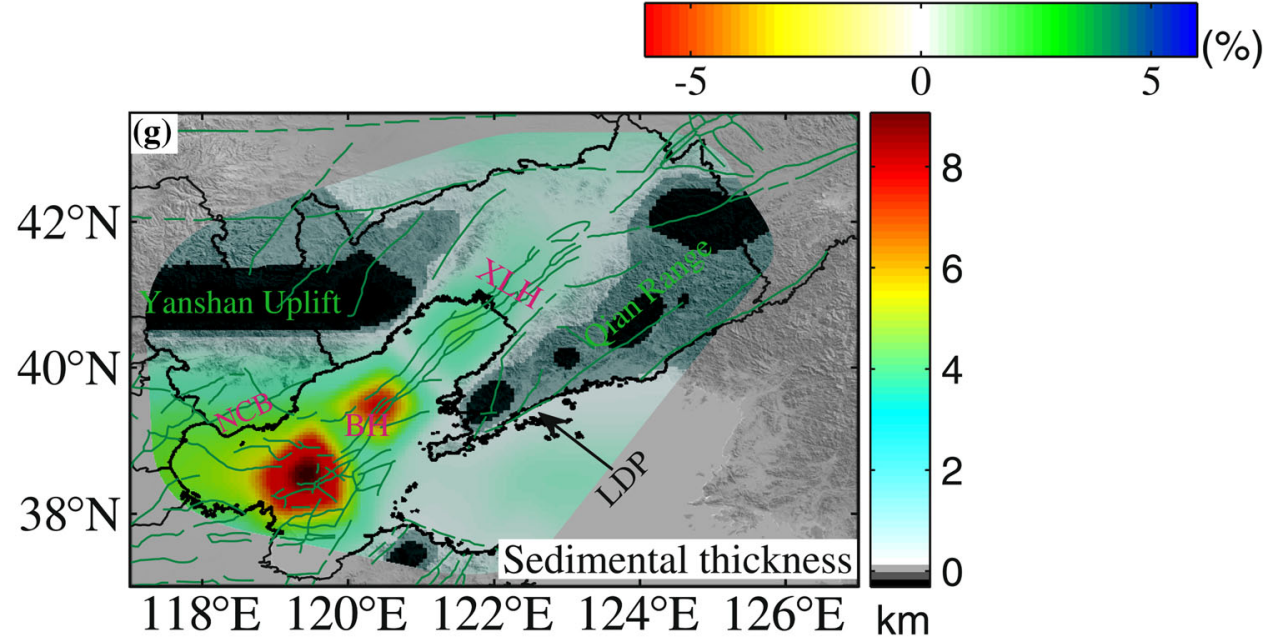

Fig. 6 The phase-velocity maps for Rayleigh and Love waves at different periods and sediment thicknesses (a-f). The period and average phase velocity of Rayleigh wave or Love wave are labelled above each panel in Fig. 6: a-f. g Sediment thicknesses based on the Crust 1.0 model. The colour bar represents the velocity anomaly in percentage compared to the average velocity. Black lines represent the boundary between provinces 
Liaodong Peninsula can be observed in both the Rayleigh and Love wave maps at periods of 9-20 s. In other words, the high-velocity anomalies extend from the surface to the lower crust, likely a result of the relatively shallow crystalline bedrock and comparatively rigid crustal media. Moreover, pronounced low-velocity anomalies in the northern part of the Liaodong Peninsula from both Rayleigh and Love wave maps at intermediate periods of 15 and $20 \mathrm{~s}$ show a remarkable correlation with crystalline bedrock composed of lower-density rocks (Liu et al. 2014) and the deeper Moho (Xing et al. 2002), respectively.

\section{Shear wave velocity structure}

We extracted the dispersion curves at each node of the $0.5^{\circ} \times 0.5^{\circ}$ grid from the Rayleigh wave phase velocities and Love wave phase velocities obtained from the previous section. By simultaneously inverting the dispersion curve data of the Rayleigh and Love waves phase velocity using the programme developed by Herrmann and Ammon (2004) with linear steps, we obtained the 1-D shear wave velocity structure under each grid node. Surface-wave dispersion curves are mostly sensitive to the shear wave velocity, and therefore, in our inversion, only the shear wave velocity in each layer is regarded as the inversion parameter, and the P-wave velocity, S-wave velocity and density are derived from the shear wave velocity with empirical formulas. Layered Earth models from the surface to $46 \mathrm{~km}$ overlying a half-space with different layer thicknesses were adopted, and the Moho depth is obtained by referring to recent receiver function studies (Luo et al. 2008; Liu et al. 2011; Zhang et al. 2013, 2015). The inversion was repeated five times, and most of grid cells could simultaneously fit both the Rayleigh and Love dispersion curves well; the fifth inversion results were used as the final 1-D profiles. Finally, the compilation of all inverted 1-D profiles was utilized to determine the 3-D shear wave velocity structures.

\subsection{Horizontal S-wave velocity profiles}

\subsubsection{S-wave velocity images of the whole study area}

Figure $7 \mathrm{a}$ shows the shear velocities averaged in the shallow crust (over depths $6-10 \mathrm{~km}$ ). The velocity distribution shows particularly strong lateral heterogeneity and corresponds to the phase-velocity map at $9 \mathrm{~s}$ (Fig. 6a, b), in excellent agreement with surface geological tectonic features. Figure $7 \mathrm{~b}$ shows the shear velocities averaged from 18 to $22 \mathrm{~km}$. A prominent feature is that the Tanlu fault in Bohai sea is characterized by pronounced higher velocities, but the stretch of the high velocities along the Tanlu fault from north to the south becomes distorted in the southern Bohai and turns to the western extension of Bohai, possibly as a result of the effect by the sinistral strike slip movement of the Zhangjiakou-Penglai fault (Qi et al. 2008); this result is consistent with the P-wave imaging result $(\mathrm{Xu}$ et al. 2016). Thus, the Tanlu fault and the Zhangjiakou-Penglai fault, as the main faults in the Bohai sea area, have seriously affected the deep structure patterns. The shear velocities averaged from 28 to $32 \mathrm{~km}$ are given in Fig. 7c. The pattern of low and high velocities, being reversed in contrast to that of the shallow crust (Fig. 7a), are strongly influenced by the thickness of the crust, the Xiaoliaohe basin, Bohai bay basin and North China basin show higher velocities than other regions, consistent with their thinner crusts. Figure $7 d$ primarily reflects the characteristics of the velocity structure near the uppermost mantle in the study region.

Next, we analyze the time-space distribution characteristic of small earthquakes in frequently occurring earthquake areas, including southern Bohai, the Haicheng region and the Tangshan region. As shown in Fig. 7, the dominant distribution of the focal depths of small earthquakes ranges from 4 to $10 \mathrm{~km}$ (Fig. 7a), followed by 18-22 km (Fig. 7b). This observation also indicates that the energy release of small earthquakes is primarily concentrated in the upper crust. The earthquake distribution in southern Bohai is denser (Fig. 7a), whereas earthquakes in Liaodong bay of the Northern Bohai sea are more isolated. The Zhangjiakou-Penglai fault and the Tanlu fault intersect to form network fault system in southern Bohai, resulting in an extremely complex structure of Earth's crust; this structure may be the primary reason for the frequent occurrence of earthquakes.

\subsubsection{S-wave velocity images of the Haicheng region}

To clearly observe the relationships between the intracrustal structure and the time-space distribution of earthquake swarm in seismically active regions including the Haicheng region (frame $\mathrm{I}$ in Fig. 1b) and the Tangshan region (frame II in Fig. 1b). The Haicheng region images at 4-10 km are shown individually in Fig. 8. The Tangshan region images at different depth ranges are shown individually in Fig. 9. Overall, Figs. 8 and 9a clearly show the following: (1) the seismicity distributions exhibit a distinctive strip-shaped appearance (the black rectangles in Figs. 8 and 9a); (2) most earthquake swarms occurred frequently with mass cluster shape in the transition strip (the pink ellipses in Figs. 8, 9a) between the high- and lowvelocity zones continuously during 2010 to 2015; and (3) only a small portion of the earthquakes occur in the lowvelocity side of the transition trip with being dispersed, implying that the low-velocity side, signifying weak and 


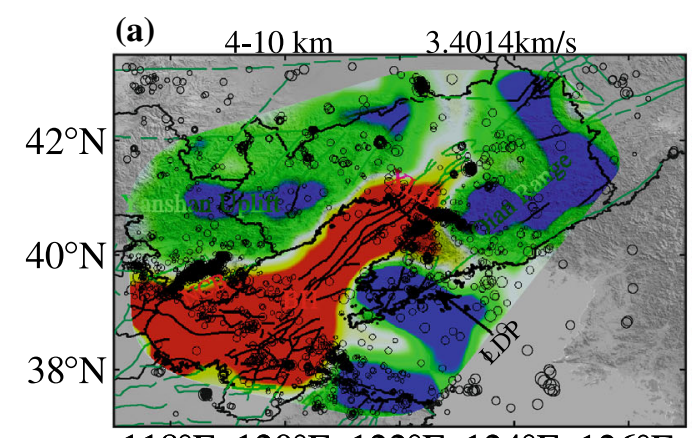

(b) $\quad 18-22 \mathrm{~km} \quad 3.5399 \mathrm{~km} / \mathrm{s}$
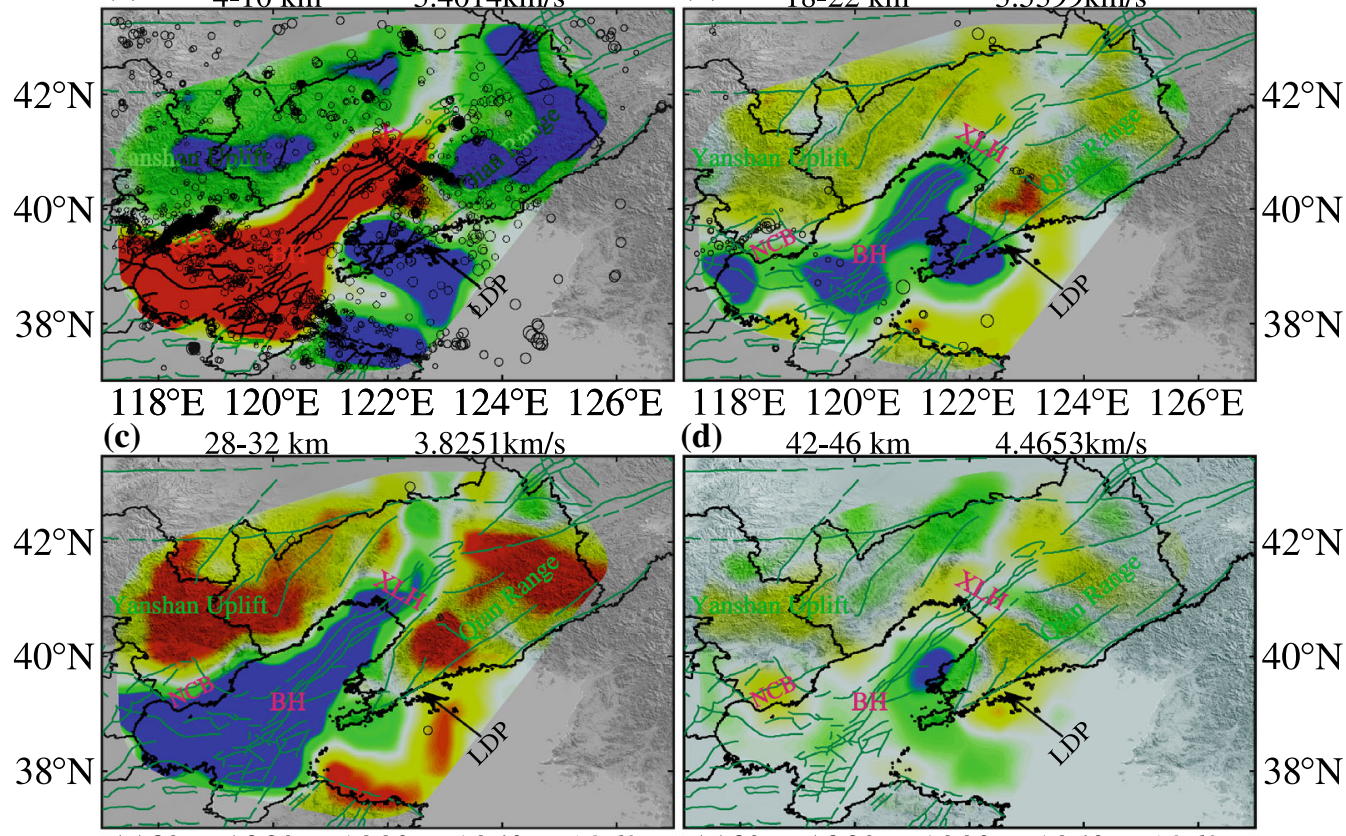

$2^{\circ} \mathrm{N}$

$40^{\circ} \mathrm{N}$

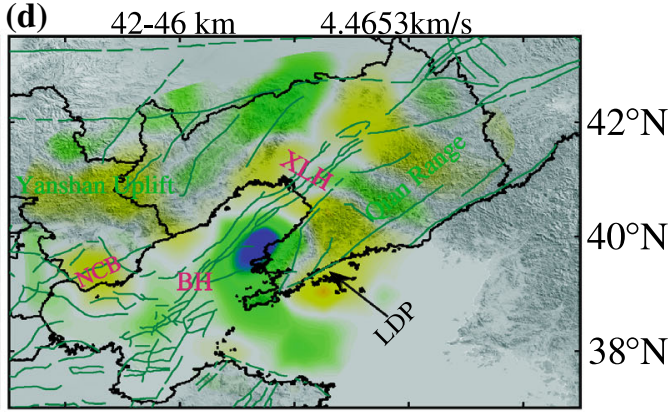

$118^{\circ} \mathrm{E} 120^{\circ} \mathrm{E} 122^{\circ} \mathrm{E} 124^{\circ} \mathrm{E} 126^{\circ} \mathrm{E}$

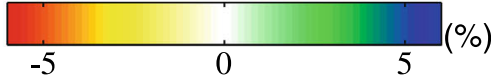

Fig. 7 The horizontal slices of the shear wave velocity structure at different depth ranges. The depth of the layer and the corresponding average velocity are shown at the top of each panel. The focal depth of the earthquake swarms is within the depth range of the corresponding horizontal slice

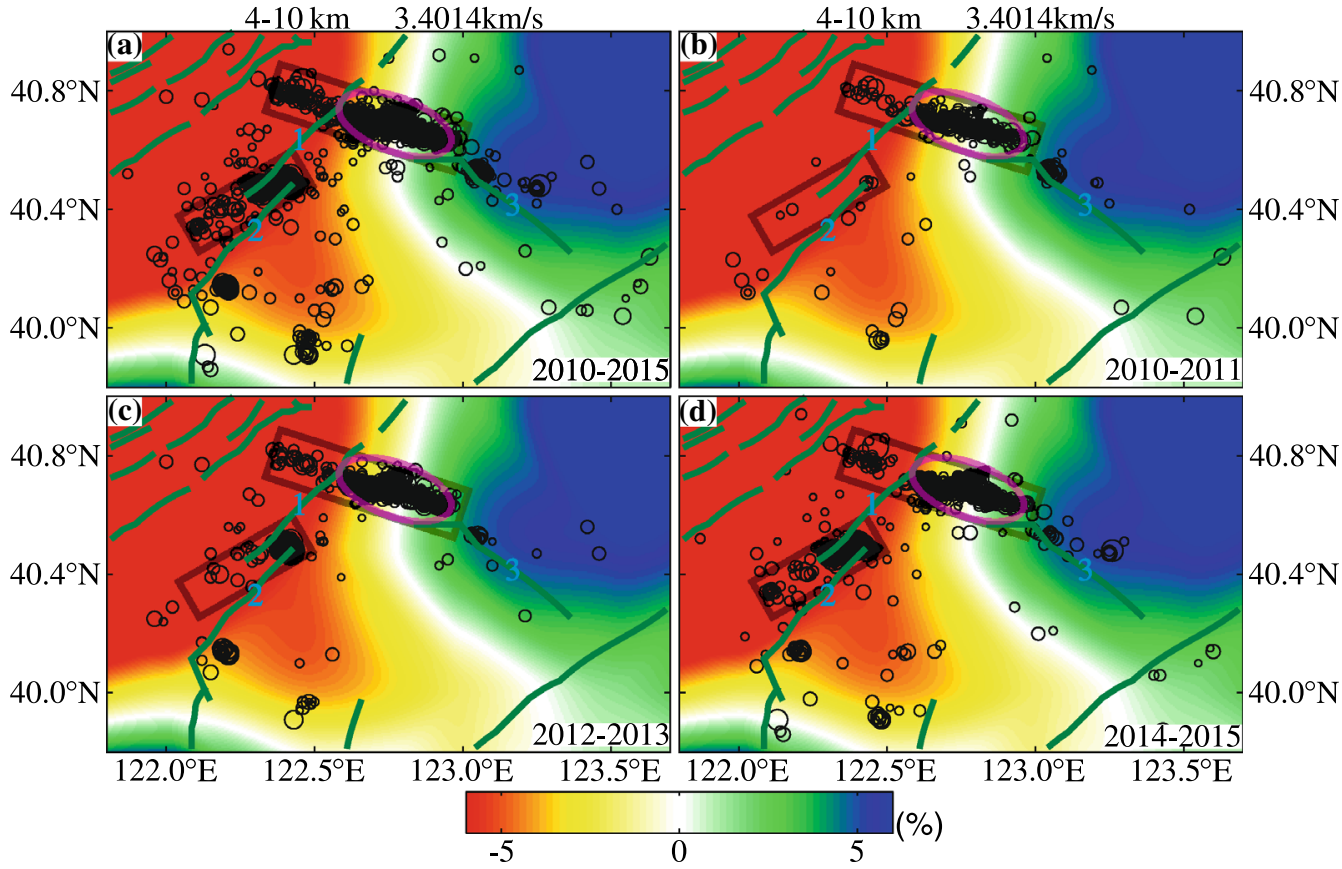

Fig. 8 Horizontal slices of the shear wave velocity structure at 4-10 km depths with earthquake swarms for different years of the Haicheng region. (1) Haicheng-Yingkou fault; (2) Jingzhou fault; and (3) Dayanghe fault. The earthquake information is the same as these in Fig. 1b, but the time ranges of earthquake occurrence are at the bottom right of each panel. The focal depth of the earthquake swarms is within 4-10 km (the scope of the profiles is shown in Fig. 1b: frame I) 

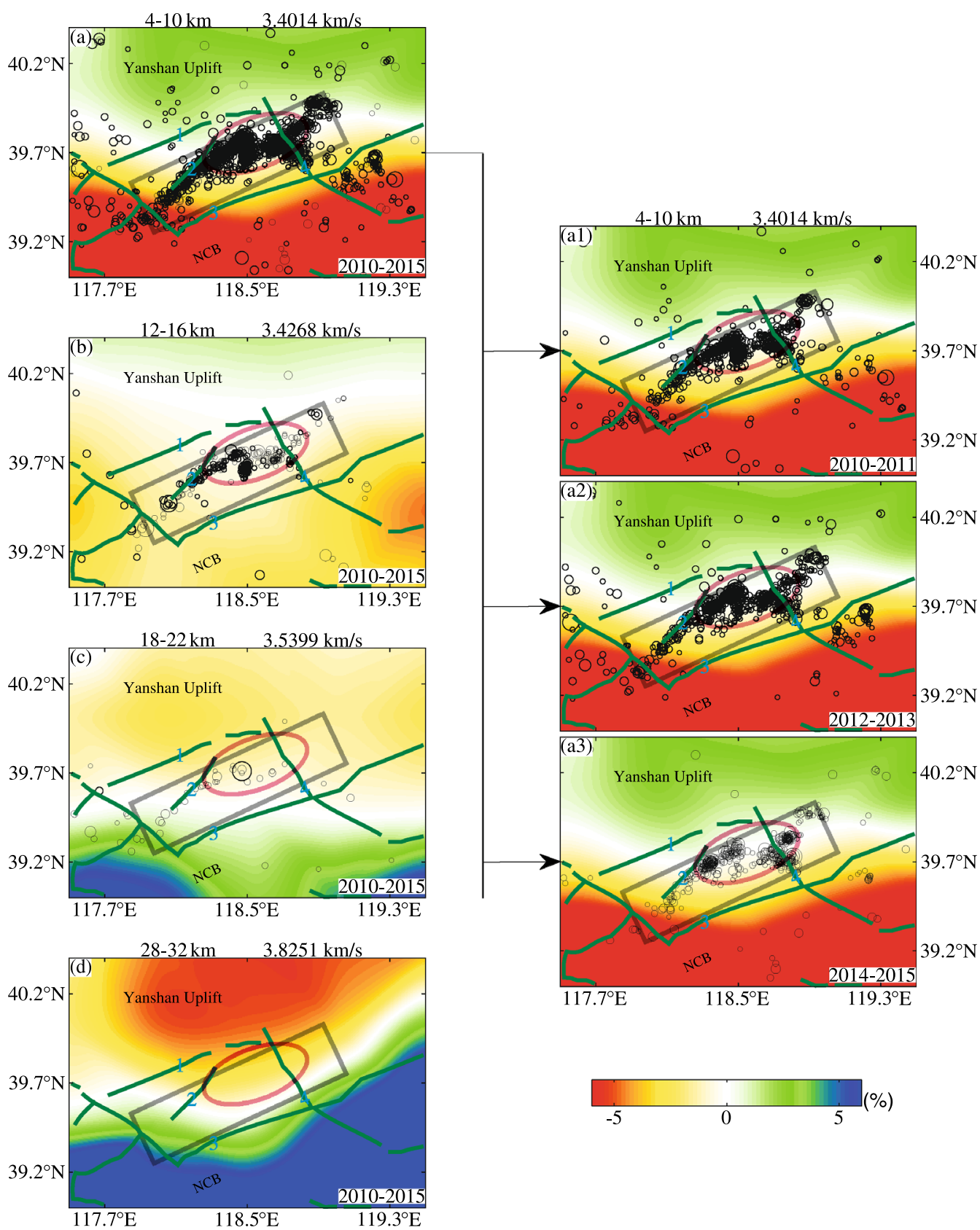

Fig. 9 Horizontal slices of the shear wave velocity structure at different depths with earthquake swarms for different years of the Tangshan region. The earthquake information is same as these in Fig. 1b, but the time ranges and the focal depth of earthquake occurrence are at the bottom right corner of each panel and on the top of each panel, respectively. a Horizontal slice at 4-10 km depths with earthquake swarms in 2010-2015, (1) Fengtai-Yejituo fault, (2) Tangshan fault, (3) Ninghe-Changli fault, and (4) Luanxian-Leting fault; b, c and d same as Fig. 9a but for 12-16 km depths, 18-22 km depths and 28-32 km depths, respectively; a1, a2 and a3 same as Fig. 9a but for years 2010-2011, years 2012-2013 and years 2014-2015, respectively. The focal depth of the earthquake swarms is within the depth range of the corresponding horizontal slice (the scope of the profiles is shown in Fig. 1b: frame II)

soft stratum, paves the way for the brittle rock fracturing or stick-slip taking place via focused stress.

The strip distributions of earthquake swarms in Haicheng region are accordance with the NW trending Jinzhou fault, the Haicheng-Yingkou fault, and the NE-trending Dayanghe fault (Fig. 8a). Moreover, the earthquake swarms in years 2010-2015 are distributed along extensions of the Dayanghe fault, suggesting that the tectonic activity of the Dayanghe fault is being continuously active and the Dayanghe fault might be continuously influenced by the NW force. While the earthquake swarms started to emerge and concentrate in the convergence position 


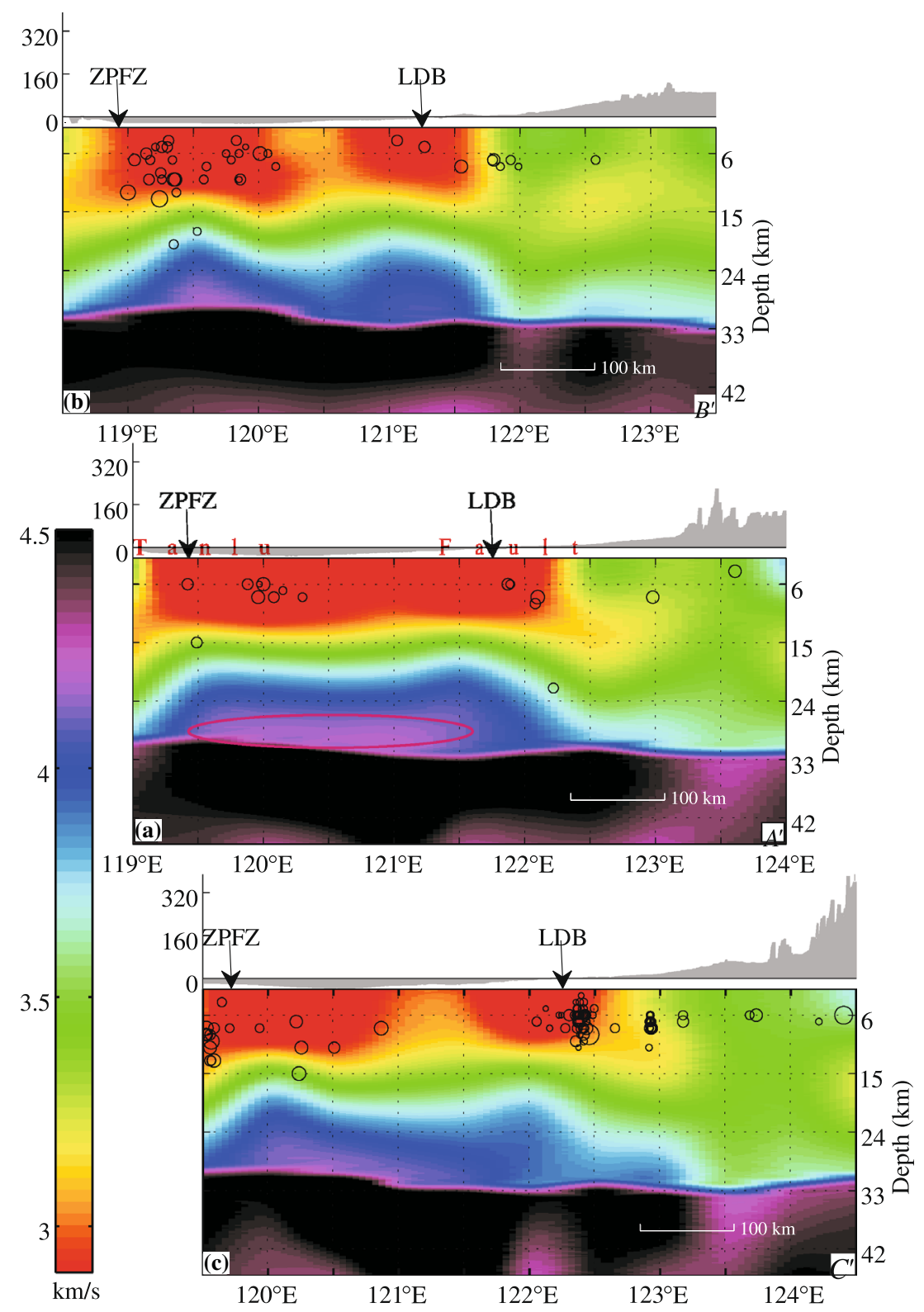

Fig. 10 The vertical slices of the shear wave velocity structure along the $A-A^{\prime}, B-B^{\prime}$ and $C-C^{\prime}$ profiles. The circles represent earthquakes whose distance from the profile is less than $0.1^{\circ}$ in each panel. ZPFZ Zhangjiakou-Penglai fault zone; $L D B$ Liaodong bay. Topography is plotted above each panel (grey area). The locations of the profiles are shown in Fig. 2a

between the northern end of the NE Jinzhou fault and the southern end of the NE Haicheng-Yingkoui fault from year 2012 (Fig. 8c), these earthquake swarms migrated to the southwest from 2012 to 2015 (Fig. 8c, d). As a result, the tectonic activity of Jinzhou fault and Haicheng-Yingkou fault appears to be active beginning in 2012 .

\subsubsection{S-wave velocity images of the Tangshan region}

The strip distributions of earthquake swarms in years 2010-2015 in the Tangshan region are in accordance with the predominant NE-trending Fengtai-Yejituo fault, the Tangshan fault, the Ninghe-Changli fault, and the NW trending Luanxian-Leting fault (Fig. 9a). More specifically, the overall strip-shape distribution (black rectangles in Fig. 9) of the earthquake swarms is consistent with the distribution of the predominant NE-trending Fengtai-Yejituo fault, the Tangshan fault, and the Ninghe-Changli fault; and the earthquake swarms mainly occurred along the Tangshan fault, along north-eastern extension of the Tangshan fault and along the Luanxian-Leting fault. Hence, we conclude that these faults play a dominant role 
in the occurrence and distribution of the earthquakes. In addition, Jia et al. (2009) proposed that the entirely different crustal structures between the stable Yanshan uplift with high velocity in the north and the incompact rift basin (NCB in our study) with low velocity in the south make the transitional zone between the tectonic zoning line of the faults and Yanshan uplift provide a favourable structural environment occurrence of earthquakes in the eastern plain region (NCP in our study) of Zhangjiakou-Bohai belt (Tangshan region in our study), which is similar to the result of our analysis. The results by the dense seismic array observations reveal that low-velocity anomalies are distributed in heterogeneous media of upper and middle crust over crust-mantle boundary with obvious block uplift, coupled with the top anomalous uplift of the upper mantle beneath the Tangshan earthquake region (Liu et al. 2007); prominent low-velocity anomalies extending from the upper crust to the lower crust in Tangshan earthquake region were also found by Duan et al. (2016), and the earthquake distribution extends from the upper crust to the uppermost lower crust (Duan et al. 2016). Therefore, Duan et al. (2016) deemed that crust deformation in the Tangshan earthquake region passes through the entire crust, with the brittle failure of upper crust and ductile deformation of lower crust, and inferred that the stress accumulation of Tangshan earthquakes is closely related to migration and deformation of the mantle material. In our study, the Tangshan earthquakes are distributed from the upper crust (Fig. 9a) to the lower crust (Fig. 9b, c) over the Moho surface with significant depth variation (Fig. 9d), these phenomena matches the above-mention previous results.

Overall, from above analysis and observation about the relationships between the intracrustal structure and the time-space distribution of earthquake swarm in Haicheng region and the Tangshan region. We conclude that the earthquake swarms are apt to occur in the transition strip between high- and low-velocity zones coinciding with the fault zones, in agreement with the predecessors' studies (e.g. Chen et al. 2014; Su et al. 2016; Qi et al. 2006); moreover, the distribution of the earthquake swarms is generally controlled by these faults. Further, continuous seismic activity is also a manifestation of the tectonic activity of the faults.

\subsection{Vertical S-wave velocity profiles}

Figure 10 shows profiles $A-A^{\prime}, B-B^{\prime}$, and $C-C^{\prime}$ of the shear wave velocity structure from surface down to $46 \mathrm{~km}$ depth across the Bohai sea and central Liaoning province; the profile $A-A^{\prime}$ also passes through the Tanlu fault Zone, and the profiles $B-B^{\prime}$ and $C-C^{\prime}$ are parallel to profile $A-A^{\prime}$ and sit on either side of the profile $A-A^{\prime}$. The following are observed in the profiles $A-A^{\prime}, B-B^{\prime}$, and $C-C^{\prime}$ in Fig. 10: (1) it is apparent that the low-elevation central and northern Bohai sea is marked by low $\mathrm{S}$-wave velocity down to approximately $13 \mathrm{~km}$ because of the very thick sedimentary cover; (2) the outstanding features are great thickness and high velocity of lower crust, with the velocities in the middle-lower crust showing gentle variation in vertical in central and northern Bohai sea, and the Moho depth along the three profiles varies slightly, and (3) higher velocities in lower crust gradually decrease and crust-mantle boundary ranges also gradually become narrow when the profiles reach the Zhangjiankou-Penglai fault zone in southern Bohai sea, which is likely due to the young formation time and the strong tectonic activity of the Zhangjiakou-Penglai fault since the Cenozoic era (Fu et al. 2004; Xu et al. 2011).

As shown in Fig. 10a, we also note the following (1) the velocity-interface undulations of the lower crust down to the uppermost mantle in central and northern the Bohai sea vary mildly; (2) the overall velocity distribution trend from the lower crust to the uppermost mantle is coincident with the trend of the Tanlu fault zone; and (3) the most apparent feature revealed by Fig. 10 is that a high-velocity thinner layer [pink ellipse in Fig. $10\left(A-A^{\prime}\right)$ ] exists at the bottom of the lower crust near Moho. The above distribution characteristics of velocity, being not shared by profiles $B-B^{\prime}$ and $C-C^{\prime}$, are apparently due to the influence of the Tanlu fault; specifically, the mantle-heat flow from the upper mantle permeated and ascended along the Tanlu fault (Zhang et al. 2007), even reaching the lower crust, and formed a high-velocity layer after long-term cooling and solidification. So these phenomena provide evidence of the underplating and reforming of the lower crust by mantle material along the Tanlu fault. The high velocities from the low crust and uppermost mantle, signifying structure stability, might strengthen the crustmantle boundary and weaken seismic activity, which corresponds to actual weak-seismic activity in the northern Bohai sea. In addition, the results of onshore-offshore surveying (Liu et al. 2015) in the southern Bohai sea also show that not only small-scale high velocity zones (HVZs) exist at the bottom of lower crust, but also low velocity zones (LVZs) exist at the top of upper mantle; velocity anomalies are inferred as the manifestation of combined effect of the collision between Yangtze and Sino-Korea block as well as the distant effect of the Pacific subduction (Fig. 14 in Liu et al. 2015). Liu et al. (2015) and Hao et al. (2013) speculated that the high-velocity bodies in the lower crust are probably the residual Yangtze crust during the continent-continental collision when the Yangtze plate subducted northward beneath the Sin-Korea plate in Early Mesozoic (Yang et al. 2012), or are the remains of 
underplating of high-density upper-mantle eclogite representing early suturing process.

\section{Conclusions}

In this paper, we conducted ambient noise seismic tomography of Liaoning province and Bohai sea in China. Both the Rayleigh and Love wave phase-velocity maps show particularly strong heterogeneity and can be explained by major geological structures. Next, the shear velocity structure was inverted from the Rayleigh wave and Love wave dispersion maps extending to a depth of $46 \mathrm{~km}$. The main results are as follows:

1. The earthquake swarms tend to concentrate in the high-low-velocity boundaries in the upper crust coinciding with fault zones in the Haicheng region and the Tangshan region, and they occur along these predominant faults or along the extension traces of these faults.

2. The lower crust downward to the uppermost mantle are featured by high velocities, with even a high-velocity thinner layer existing at the bottom of the lower crust near Moho, in the central and northern the Bohai sea along the Tanlu fault. These phenomena could be caused by the intrusion of mantle material ascending along the Tanlu fault.

Acknowledgements We express our sincere thanks to the "State Earthquake Information Service-Data Management Center" for providing the data. This research is supported by Sino-Probe-Deep Exploration in China (SinoProbe-09-04: 201311195). We appreciate Dr. Huajian Yao for providing the codes for ambient noise crosscorrelation, dispersion analysis and tomography used in this study.

Open Access This article is distributed under the terms of the Creative Commons Attribution 4.0 International License (http://crea tivecommons.org/licenses/by/4.0/), which permits unrestricted use, distribution, and reproduction in any medium, provided you give appropriate credit to the original author(s) and the source, provide a link to the Creative Commons license, and indicate if changes were made.

\section{References}

Campillo M, Paul A (2003) Long-range correlations in the diffuse seismic coda. Science 299(5606):547-549

Chen CX, Zhao DP, Wu SG (2014) Crust and upper mantle structure of the New Madrid Seismic Zone: insight into intraplate earthquakes. Phys Earth Planet Int 230:1-14

Cheng C, Chen L, Yao HJ, Jiang M, Wang B (2011) Distinct variations of crustal shear wave velocity structure and radial anisotropy beneath the North and tectonic implications. Gonwan Res 23(2013):25-38

Duan YH, Wang FY, Zhang XK, Lin JY, Liu Z, Liu BF, Yang ZX, Guo WB, Wei YH (2016) The three dimensional crustal velocity structure model of the middle-eastern North China Craton (HBCrust1.0). Sci China Earth Sci 59:1477-1488. doi:10.1007/ s11430-016-5301-0

Fu ZX, Liu J, Liu GP (2004) On the long-term seismic hazard analysis in the Zhangjiakou-Penglai zone, China. Tectonophysics 390(2004):75-83

Hao TY, You QY, Liu LH, Lv CC, Xu Y, Li ZW, Zhao CL, Zheng YP, Liu CG, Han GZ (2013) Joint land-sea seismic survey and research on the deep structures of the Bohai Sea areas. Acta Oceanal Sin 32:13-24

Herrmann RB, Ammon CJ (2004) Surface waves, receiver functions and crustal structure. Computer Pro grames in Seismology, Version 3.30, Saint Louis University.http://www.eas.slu.edu/ People/RBHerrmann/CPS330.html2015-06-01

Huang ZX, Xu Y, Hao TY, Peng YJ, Zheng YJ (2009) Surface wave tomography of lithospheric structure in the seas o f east China. Chin J Geophys 52(2):379-389 (in Chinese with English abstract)

Jia SX, Zhang CK, Zhao JR, Fang SM, Liu Z, Zhao JM (2009) Crustal structural of the rift-depression basin and Yanshan uplift in the northeast part of North China. Chin J Geophys 52(1):99-110 (in Chinese with English abstract)

Jiang DD, Jiang WW, Xu Y, Hao TY, Hu WJ, Feng J (2014) Characteristics of crustal structure and their relation with maj or earthquakes in western China. Chin J Geophys 57(12):4029-4040. doi:10.6038/cjg20141215 (in Chinese with English abstract)

Laske G, Masters G, Ma Z, Pasyanos M (2015) Up on CRUST1.0: A 1-degree global model of Earth's crust. Geo Phys Res Abstracts 15: 2658

Li ZW, Xu Y, Hao TY, Liu JS, Zhang L (2006) Seismic tomography and velocity structure in the crust and upper mantle around Bohai Sea. Chin J Geophys 49(3):797-804 (in Chinese with English abstract)

Li HY, Su W, Wang CY, Huang ZX (2009) Ambient noise Rayleigh wave tomography in Western Sichuan an d Eastern Tibet. Earth Planet Sci Lett 282(1-4):201-211

Li HY, Su W, Wang CY, Huang ZX, Lv ZY (2010a) Ambient noise Love wave tomography in the eastern margin of the Tibetan plateau. Tectonophysics 491(1-4):194-204

Li SZ, Suo YH, Dai LM, Liu LP, Jin C, Liu X, Hao TY, Zhou LH, Liu BH, Zhou JT, Jiao Q (2010b) Development of the Bohai Bay and destruction of the North China Craton. Earth Sci Front 17(4):064-089 (in Chinese with English abstract)

Li ZW, Hao TY, Xu Y (2011) Uppermost mantle structure of the North China Craton: constrains from interstation Pn travel time difference tomography. Chin Sci Bull 56(16):1691-1699. doi:10. 1007/s11430-011-4203-4

Lin FC, Morgan PM, Michael HR (2007) Surface wave tomography of the western United States from ambient seismic noise: rayleigh and Love wave phase velocity maps. Geophys J Int. doi:10.1111/j.1365-246X.2008.03720

Lin FC, Schmandt B, Tsai VC (2012) Joint inversion of Rayleigh wave phase velocity and elli pticity using USArray: Constraining velocity and density structure in the upper crust. Geophys Res Lett. doi:10.1029/2012GL052196.2012

Liu QY, Wang J, Chen JH, Li SC, Guo B (2007) Seismogenic tectonic environment of 1976 great Tangshan earthquake: results given by dense seismic array observations. Earth Sci Front 14(6):205-213 (in Chinese with English abstract)

Liu QL, Wang CY, Yao ZX, Chang LJ, Lou H (2011) Study on crustal thickness and velocity ratio in mid-western North China Craton. Chin J Geophys 54(9):2213-2224. doi:10.3969/j.issn. 0001-5733.2011.09.003 (in Chinese with English abstract)

Liu XY, Xue LF, Liu ZH, Jiang Y, Li TL (2014) The deep geological structure characteristics of parts of Liaoji paleorift. Seismol 
Geol. doi:10.3969/j.issn.0253-4967.2014.01.07 (in Chinese with English abstract)

Liu LH, Hao TY, Lü CC, You QY, Pan J, Wang FY, Xu Y, Zhao CL, Zhang JS (2015) Crustal structure of Bohai Sea and adjacent (North China) from two onshore-off shore wide-angel seismic survey lines. J Asian Earth Sci 98:457-469

Lü ZQ, Lei JS, Zhou ZG (2016) Pn-wave velocity and anisotropy around the Bohai Sea areas. Chin J Geophys 59(6):2047-2055. doi:10.6038/cjg20160611 (in Chinese with English abstract)

Luo Y, Chong JJ, Ni SD, Chen QF, Chen Y (2008) Moho depth and sedimentary thickness in Capitial region. Chin J Geophys 51(4):1135-1145 (in Chinese with English abstract)

Obermann A, Froment B, Camillo M, Larose E, Planes T, Valette B, Chen JH, Liu QY (2014) Seismic noise correlations to image structural and mechanical changes associated with the $M_{\mathrm{S}} 7.9$ 2008 Wenchuan earthquake. J Geophys Res Solid Earth 119:3155-3168. doi:10.1002/2013JB010932

Qi JF, Yang Q (2010) Cenozoic structural deformation and dynamic processes of the Bohai Bay basin province, China. Mar Pet Geol 27:757-771

Qi C, Zhao DP, Chen Y, Chen QF, Wang BS (2006) 3-D P and S wave velocity structures and their relationship to strong earthquakes in the Chinese capital region. Chin J Geophys 49(3):805-815 (in Chinese with English abstract)

Qi JF, Zhou XH, Deng RJ, Zhang KX (2008) Structural characteristics of the Tan-Lu fault zone in Cenozoic basins offshore the Bohai Sea. Sci China Earth Sci 51(2):20-31

Ritzwoller MH, Levshin AL (1998) Surface wave tomography of Eurasia: group velocites. J Geophys Res 1(03):4839-4878

Roux P, Sabra KG, Kuperman WA (2005) Ambient noise cross correlation in free space: theoretical approach. J Acoust Soc Am 117(1):79-84

Sabra KG, Gerstoft P, Roux P, Kuperman WA (2005) Extracting timedomain Greens function estimates from ambient seismic noise. Geophys Res Lett 32:L03310. doi:10.1029/2004GL021862

Shapiro NM, Campillo M (2004) Emergence of broadband Rayleigh waves from correlations of the ambient seismic noise. Geophys Res Lett 31(7):L07614. doi:10.1029/2004GL019419

Shapiro NM, Campillo M, Stehly L, Ritzwoller MH (2005) Highresolution surface-wave tomography from ambient seismic noise. Science 307(5717):1615-1618

Su DL, Fan JK, Wu SG, Chen CX, Dong XN, Chen SJ (2016) 3D P wave velocity structures of crust and mantle and their relationship with earthquakes in the Shangdong area. Chin J Geophys 59(4):1335-1349. doi:10.6038/cjg20160415 (in Chinese with English abstract)

Sun XL, Song XD, Zheng SH, Yang YJ, Ritzwoller MH (2010) Three dimensional shear wave velocity structure of the crust and upper mantle beneath China from ambient noise surface wave tomography. Earthq Sci 23(44):9-4693

Tarantola A, Nercessian A (1984) Three-dimensional inversion with blocks. Geophys J R Astr Soc 76(2):299-306

Tian Y, Zhao DP, Sun RM, Teng JW (2009) Seismic imaging of the crust and upper mantle beneath the China North. Phys Earth Planet Inter 172(2009):169-182

Wang XF, Li ZJ, Chen BL, Chen XH, Dong SW, Zhang Q (2000) On Tan-Lu fault zone. Geological Publishing House, Beijing. pp. 1-374. (in Chinese)

Wang CZ, Wu JP, Fang LH, Wang WL (2013) The relationship between wave velocity structure around Yushu earthquake source region and the distribution of aftershocks. Chin J Geophys 56(12):4072-4083. doi:10.6038/cjg20131212 (in Chinese with English abstract)

Weaver RL (2005) Information from seismic noise. Science 307(5715):1568-1569
Weaver RL, Lobkis OI (2004) Diffuse fields in open systems and the emergence of the Green's function correlation in free space: theoretical approach. J Acoust Soc Am 116(5):2731-2734

Xing JS, Liu JH, Zhao JQ (2002) Deep-seated tectonics in the North China intraplate. Earthq Res Shanxi 4:3-12 (in Chinese with English abstract)

Xu J, Zhou BG, Ji FJ, Gao XL, Lv YJ, Wang MM, Chen GG (2011) A primary study on the neotectonic of the Bohai area in China. Acta Petrol Sin 32:442-449 (in Chinese with English abstract)

Xu T, Zhang MH, Tian XB, Zheng Y, Bai ZM, Wu CL, Zhang ZJ, Teng JW (2014) Upper crustal velocity of Lijiang-Qingzhen profile and its relationship with the seismogenic environment of the $M_{\mathrm{S}} \quad 6.5$ Ludian earthquake. Chin J Geophys 57(9):3069-3079. doi:10.6038/cjg20140932 (in Chinese with English abstract)

Xu Y, Wang S, Meng XC (2016) Tomographic evidence of the TanLu fault zone in the Bohai Sea of eastern China. Scientia Sinca Terrae 46(6):845-856 (in Chinese with English abstract)

Yang KF, Fan HR, Santosh M, Hu FF, Wilder SA, Lan TG, Lu LN, Liu YS (2012) Reactivation of the Archean lower crust: implications for zir con geochronology, elemental and Sr-NdHf isotopic geochemistry of late Mesozoic granitoids from northwestern Jiaodong Terrane, the North China Craton. Lithos 146-147:112-127

Yao HJ, van der Hilst RD, de Hoop MV (2006) Surface-wave array tomography in SE Tibet from ambient seismic noise and twostation analysis-I. Phase velocity maps. Geophys J Int 166(2):732-744

Yao HJ, Beghein C, ven der Hils RD (2008) Surface wave array tomography in SE Tibet from ambie nt seismic noise and twostation analysis-II, crustal and upper-mantle structure. Geophys J Int 173(1):205-219

Yao HJ, van der Hils RD, Montagner J-P (2010) Heterogeneity and anisotropy of the lithosphere of SE Tibet from surface wave array analysis. J Geophys Res 115:B2307. doi:10.1029/ 2009JB007142

Yu XW, Chen YT, Zhang H (2010) Three-dimensional crustal P-wave velocity structure and seismicity analysis in BeijingTianjin-Tangshan region. Chin J Geophys 53(8):1817-1828. doi:10.3969/j.issn.0001-5733.2010.08.007 (in Chinese with English abstract)

Yu N, Wang XB, Hu XY, Cai XL, Kan A, Zhao N (2014) The deep geophysical structure of the middle section of the Longmen mountains tectonic belt and its relationship to the Wenchuan earthquake. Acta Geol Sin 88(2):483-497

Zhang L, Liu JS, Hao TY, Liu JH, Xu Y (2007) Seismic tomography of the crust and upper mantle in the Bohai Bay and its adjacent regions. Sci China Earth Sci 50:1810-1822

Zhang GC, Wu QJ, Pan JT, Zhang FX, Yu DX (2013) Study of crustal structure and Poisson ratio of NE China by H-K stack and CCP stack methods. Chin J Geophys 56(12):4048-4094. doi:10.6038/ cjg20131213 (in Chinese with English abstract)

Zhang JS, Wang FY, Liu BF, Wang SJ, Zhao JR, Zhang CK, Li YQ, Liu QX, Li L (2014) A study of the crustal-mantle velocity structure beneath the Yushu earthquake zone and its adjacent areas. Seismol Geol. doi:10.3969/j.issn.0253-4967.2014.02.004 (in Chinese with English abstract)

Zhang YY, Gao Y, Shi YT, Liu K (2015) Crustal thickness and Poisson's ratio beneath Zhangjiakou-Bohai seismic active belt and its neighboring regions. Acta Seismol Sinica 37(4):541-553. doi:10.11939/jass.04.002 (in Chinese with English abstract)

Zheng SH, Sun XL, Song XD, Liu K (2008) Surface wave tomography of China from ambient seismic noise correlation. Geochem Geophys Geosyst. doi:10.1029/2008GC001981 
Zheng XF, Ouyang B, Zhang DN, Yao ZX, Liang JH, Zheng J (2009) Technical system construction of Data Backup Center for China Seismograph Network and the data support to researches on the Wenchuan earthquake. Chin J Geophys 52(5):1412-1417. doi:10.3969/j.issn.0001-5733.2009.05.031 (in Chinese with English abstract)
Zhu FM (1980) The Haicheng Earthquake in 1975. Seismological Press, Beijing, pp 165-195 (in Chinese)

Zhu RX, Chen L, Wu FY, Liu JL (2011) Time, scale and mechanism of the destruction of the North China Craton. Sci China Earth Sci 54:789-797. doi:10.1007/s11430-011-4203-4 